\title{
G-CSF promotes autophagy and reduces neural tissue damage after spinal cord injury in mice
}

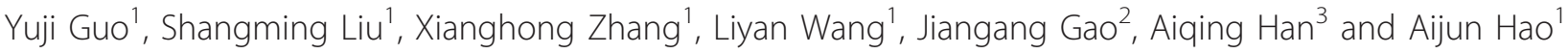

\begin{abstract}
Granulocyte colony-stimulating factor (G-CSF) was investigated for its capacity to induce autophagy and related neuroprotective mechanisms in an acute spinal cord injury model. To accomplish this goal, we established a mouse spinal cord hemisection model to test the effects of recombinant human G-CSF. The results showed that autophagy was activated after spinal cord injury and G-CSF appears to induce a more rapid activation of autophagy within injured spinal cords as compared with that of non-treated animals. Apoptosis as induced in mechanically injured neurons with G-CSF treatment was enhanced after inhibiting autophagy by 3-methyladenine (3-MA), which partially blocked the neuroprotective effect of autophagy as induced by G-CSF. In addition, G-CSF inhibited the activity of the NF- $k B$ signal pathway in neurons after mechanical injury. We conclude that G-CSF promotes autophagy by inhibiting the NF- $K B$ signal pathway and protects neuronal structure after spinal cord injury. We therefore suggest that G-CSF, which rapidly induces autophagy after spinal cord injury to inhibit neuronal apoptosis, may thus provide an effective auxiliary therapeutic intervention for spinal cord injury.

Laboratory Investigation (2015) 95, 1439-1449; doi:10.1038/labinvest.2015.120; published online 2 November 2015
\end{abstract}

Spinal cord injury (SCI) destroys cellular structures causing cell death and inflammation. The initial stages of SCI instigate a progressive cascade of secondary injuries, which exacerbate the extent of this destruction. ${ }^{1-3}$ In specific, apoptosis represents a major component of such secondary injuries and an impediment to functional recovery after SCI. ${ }^{4,5}$ In addition to apoptosis, recent findings have revealed that autophagy represents another mechanism involved with regulating programmed cell death after SCI. 6,7

Autophagy has an important role in the degradation of cytoplasmic constituents via the autophagosomal-lysosomal pathway. ${ }^{8,9}$ This pathway provides a means through which damaged organelles, toxic agents and long-lived, unwanted proteins are degraded and recycled, thereby maintaining cellular homeostasis. Abnormalities in autophagy have been implicated in SCI, as well as in many chronic neurodegenerative diseases, such as Alzheimer's disease, Parkinson's disease and amyotrophic lateral sclerosis. ${ }^{10-12}$ In animal models of these conditions, boosting autophagy appears to retard the progression of the disease by facilitating removal of misfolded proteins that have a pathogenic role. However, it has also been reported that activation of autophagy induced cell death in a myocardial ischemia and reperfusion model. ${ }^{13}$ Moreover, in traumatic brain injury and cerebral ischemia autophagy has been shown to be involved in the induction of cell death. ${ }^{14,15}$ Whether autophagy is protective or detrimental for neural tissue after SCI remains to be determined. Accordingly, a better understanding of autophagy's role in SCI will help identify new targets for treatment.

Granulocyte colony-stimulating factor (G-CSF), produced by monocytes, fibroblasts and endothelial cells, is a low molecular weight glycoprotein. ${ }^{16}$ G-CSF binds with a specific receptor, G-CSF receptor (G-CSFR) and promotes the proliferation and differentiation of granulocyte hemopoietic progenitor to protect neutrophils from apoptosis. G-CSFR is present within the $\mathrm{CNS}^{17}$ and increasing evidence has revealed that G-CSF may inhibit neuronal apoptosis associated with neural injury/disease and, in this way, promote neuroprotective effects. ${ }^{18-20}$ In particular, G-CSF has been shown to exert beneficial effects via an anti-autophagic mechanism in cardiomyopathic hamster models. ${ }^{21}$ Based upon these findings, the potential for G-CSF to function as a

\footnotetext{
${ }^{1}$ Key Laboratory of the Ministry of Education for Experimental Teratology, Department of Histology and Embryology, Shandong University School of Medicine, Jinan, China; ${ }^{2}$ Institute of Developmental Biology, College of Life Science, Shandong University, Jinan, China and ${ }^{3}$ Department of Obstetrics, Maternal and Children Health Hospital of Jinan City, Jinan, China

Correspondence: Professor A Han, Department of Obstetrics, Maternal and Children Health Hospital of Jinan City, 2\#, Small Jingsan Road, Jinan, Shandong 250001, China or Professor A Hao, Key Laboratory of the Ministry of Education for Experimental Teratology, Department of Histology and Embryology, Shandong University School of Medicine, 44\#, Wenhua Xi Road, Jinan, Shandong 250012, China.

E-mail: haq6888@163.com or aijunhao@sdu.edu.cn

Received 20 January 2015; revised 24 April 2015; accepted 28 April 2015
} 
neuroprotectant in acute SCI attracted our attention. Therefore, in this report, we examined whether G-CSF affects autophagy of neurons and the locomotor recovery process after SCI. To accomplish this goal, we first established a mouse spinal cord hemisection model. These mice were then injected with recombinant human G-CSF (rhG-CSF) and examined for the activation of autophagy at different time points under conditions with or without G-CSF treatment in vivo. In addition, the possible pathway of G-CSF neuroprotection after neuronal mechanical injury in vitro was assessed.

\section{MATERIALS AND METHODS} Animals

Fifty-four female Kunming mice $(30 \pm 5 \mathrm{~g})$ obtained from the Laboratory Animal Center at Shandong University were used in this experiment. Mice were bred and housed under standard laboratory conditions at $23^{\circ} \mathrm{C}$ with an alternating 12-h light-dark cycle and free access to a commercial diet. All animal experiments were approved by the Shandong University Animal Care Committee.

\section{Spinal Cord Hemisection}

Spinal cord hemisection was performed as described previously. 22,23 Briefly, mice were anesthetized with $10 \%$ chloral hydrate. Dorsal laminectomy was performed to expose spinal cord segments T9-T11 using a superficial vein at T5-T6 as a landmark. The dura was incised $(1 \mathrm{~mm})$ at the midline of T10. A complete hemisection of the right hemicord at T10 was performed with the tip of iridectomy scissors. After surgery, the muscles and skin were sutured in layers and an antibiotic (Gentamicin, $1000 \mathrm{u}$ ) was administered subcutaneously. Paralysis of the right hindlimb as assessed at 1 day after spinal cord hemisection indicated that the surgery was successful and an effective model was generated. Each mouse received manual bladder manipulation twice daily until recovery of sphincter control was present.

\section{Drug Treatment}

The fifty-four mice were divided randomly into two groups, a G-CSF-treated group and an injury control group. The G-CSF-treated group was injected subcutaneously with rhG-CSF (50 $\mu \mathrm{g} / \mathrm{kg}$ day, Chugai Pharmaceutical, Tokyo, Japan) for 3 consecutive days after spinal cord hemisection. ${ }^{24}$ The injury control group was injected subcutaneously with an equal volume of phosphate-balanced solution (PBS) for 3 consecutive days after spinal cord hemisection. A sample of six mice were used for each time point as assessed at 1, 3, 5 or 7 days post-injury, with three mice used for immunohistological studies and three for western blots. Another group of six mice were used for electron microscopy as evaluated at 5 days post-injury. The animals were also assessed for motor function at specific time points post-SCI, and subsequently killed for histological or biochemical measurements.

\section{Neuronal Cultures}

Spinal cords were isolated from adult Kunming mice as described previously. ${ }^{25}$ Briefly, mice were killed and the spinal cord was isolated in D-Hank's balanced salt solution. Spinal cord tissue was then dissociated into a cell suspension by mechanical disruption and trypsinization $(0.125 \%$ trypsin and $0.02 \%$ ethylenediaminetetraacetic acid). Cells were seeded at a density of $1 \times 10^{6}$ cells $/ \mathrm{ml}$ onto poly-L-lysinecoated glass coverslips or tissue culture dishes in serum-free Neurobasal-A medium (containing 2\% B27). After 7 days in culture, the cells were used for mechanical scratching.

\section{Mechanical Injury Model in Neuronal Cultures}

Scratch insult was performed on cultured spinal cord neurons as described previously. ${ }^{26}$ Cell bodies and processes were cut mechanically with a cataract knife. In order to standardize the damage within each well, a self-made cardboard painting grid with $2 \mathrm{~mm}$ intervals was placed beneath the transparent plastic plates. The blade was then moved slowly and gently along the gridlines to induce scratching. For one group, G-CSF (100 ng/ml) was then added into the cultures (G-CSF group). In a second group, $2 \mathrm{mM}$ of 3-methyladenine (3-MA, Sigma-Aldrich, St Louis, MO, USA) was administered at $10 \mathrm{~min}$ before mechanical injury followed by $100 \mathrm{ng} / \mathrm{ml}$ G-CSF after mechanical injury (3-MA group). The third group served as the control and received an equal volume of saline as that of the G-CSF administration of the injury groups.

For NF- $\kappa \mathrm{B}$ inhibitor test, we added $100 \mathrm{ng} / \mathrm{ml} \mathrm{G-CSF}$ into culture system (G-CSF group). In another group, we added $10 \mu \mathrm{M}$ BAY11-7082 (NF- $\kappa \mathrm{B}$ inhibitor, Sigma-Aldrich, St Louis, MO, USA) into culture system after mechanical injury (BAY11 group). The third group served as the control and received an equal volume of saline after mechanical injury (control group).

\section{Tissue Processing}

For immunohistological assays, mice were perfused transcardially with ice-cold $4 \%$ paraformaldehyde in $0.1 \mathrm{~m}$ phosphate buffer $(\mathrm{pH}=7.2)$ at $1,3,5$ or 7 days after spinal cord hemisection. The spinal cords were removed and post-fixed in the same fixative. Fifteen-micrometer sections were prepared on a cryostat. For western blot assays, mice were killed at 1, 3, 5 or 7 days after spinal cord hemisection, spinal cords were quickly frozen in liquid nitrogen and maintained at $-80^{\circ} \mathrm{C}$.

\section{Immunohistochemical Staining}

To assess LC3B protein expression in lesioned tissue, immunohistochemistry was performed following standard methods. Sections were exposed for $30 \mathrm{~min}$ at room temperature to normal goat serum $(10 \%$ in phosphatebuffered saline, $\mathrm{pH} 7.3$ ) with $0.2 \%$ Triton X-100 for blocking of the sections. The sections were then incubated with primary antibodies against rabbit LC3B (1:100; Cell Signaling, 
Danvers, MA, USA) at $4{ }^{\circ} \mathrm{C}$ overnight followed by staining with an $\mathrm{ABC}$ kit (Vector Laboratories, Burlingame, CA, USA). The sections were counterstained with hematoxylin.

\section{Double Immunofluorescence Staining}

For determination of LC3B localization within spinal cords, double immunofluorescence staining was performed following standard procedures. Briefly, sections were subjected to normal goat serum (10\% in PBS, pH 7.3) with $0.2 \%$ Triton X-100 for $30 \mathrm{~min}$ at room temperature. The sections were then incubated with primary antibodies against mouse MAP2 (1:200; Millipore, Billerica, MA, USA) or GFAP (1:200; Abcam, Cambridge, MA, USA) and primary antibodies against rabbit LC3B (1:100; Cell Signaling) at $4{ }^{\circ} \mathrm{C}$ overnight followed by staining with fluorescence-conjugated goat anti-mouse/rabbit IgG (1:100; Sigma-Aldrich, ) for $1 \mathrm{~h}$ at $37^{\circ} \mathrm{C}$. Nuclei were counterstained with 4',6-diamidino-2-phenylindole (DAPI) (1:1000; Invitrogen, Carlsbad, CA, USA). Adjacent sections were single stained immunohistochemically for MAP2, GFAP or LC3B in order to validate the immunofluorescence labeling. Fluorescence images were collected using a Leica microscope.

\section{Terminal Deoxynucleotidyl Transferase-Mediated dUTP Nick-End Labeling (TUNEL) Assay}

TUNEL staining was performed following the manufacturer's instructions (KeyFEN, NJ, CHN). Briefly, sections were incubated with $0.1 \%$ Triton X-100 in $0.1 \%$ sodium citrate. After rinsing, sections were incubated in TdT Reaction Mixture for $1 \mathrm{~h}$ at $37^{\circ} \mathrm{C}$ in a humidified chamber and then counterstained with DAPI for $10 \mathrm{~min}$. Fluorescence images were collected for analysis using a Leica microscope and counted in 30 fields. Sections near the lesion epicenter (from $300 \mu \mathrm{m}$ rostral to $300 \mu \mathrm{m}$ caudal) were excluded from histological assessment, as tissue destruction was too severe to count neurons precisely. Cell counting included the area from either 300 to $800 \mu \mathrm{m}$ rostral or 300 to $800 \mu \mathrm{m}$ caudal to the lesion epicenter as previously described. ${ }^{19}$ The examiners were blinded as to the treatment condition of the mice.

\section{Electron Microscopy}

At 5 days after spinal cord hemisection, the mice were overdosed by an intraperitoneal injection of $100 \mathrm{mg} / \mathrm{kg}$ sodium pentobarbital. The mice were perfused transcardially with normal saline, followed by $2 \%$ paraformaldehyde and $2.5 \%$ glutaraldehyde in cacodylate buffer. For electron microscopic analyses, spinal cord segments containing the injured site were removed and post-fixed in $2.5 \%$ glutaraldehyde at $4{ }^{\circ} \mathrm{C}$ overnight. The spinal cords were then cut with a sharp razor blade and serial $1 \mathrm{~mm}$ transverse slices surrounding the injury site were removed. These tissue slices were post-fixed in $1 \%$ osmium tetroxide for $1 \mathrm{~h}$ at $4{ }^{\circ} \mathrm{C}$, rinsed in PBS, dehydrated in a graded series of alcohol and propylene oxide solutions and embedded in Epon. Blocks showing a predominantly transverse orientation of the injured spinal cords were selected from toluidine-blue-stained thick sections. Ultrathin $(70 \mathrm{~nm})$ sections were prepared on an ultramicrotome (Ultracut R, Leica, Heerbrugg, Switzerland) with a diamond knife, stained with uranyl acetate and lead citrate and viewed using an electron microscope (JEM-1200, JOEL, Tokyo, Japan).

\section{Crystal Violet Staining}

Crystal violet staining was performed following standard methods at 5 days after spinal cord hemisection. Sections were incubated with $0.1 \%$ cresyl violet solution (SigmaAldrich) for 5-10 min, then differentiated in 95\% ethyl alcohol for 2-30 min and assessed microscopically.

\section{Staining}

Monodansylcadaverine (MDC) staining was also performed using a procedure similar to that described previously. ${ }^{27}$ Neurons were fixed with $4 \%$ PFA for $10 \mathrm{~min}$ at $37^{\circ} \mathrm{C}$ at $24 \mathrm{~h}$ after mechanical injury, and then incubated for $10 \mathrm{~min}$ at $37^{\circ} \mathrm{C}$ with $50 \mu \mathrm{M} \mathrm{MDC}$, an autofluorescent compound that labels autophagic vacuoles. Fluorescence images were collected using a Leica microscope.

\section{Western Blot Analysis}

Spinal cord tissue was washed with cold PBS and lysed in cold lysis buffer containing $10 \mathrm{mM}$ Tris- $\mathrm{HCl}, \mathrm{pH} 8.0,240 \mathrm{mM}$ $\mathrm{NaCl}, 5 \mathrm{mM}$ EDTA, $1 \mathrm{mM}$ dithiothreitol, $0.1 \mathrm{mM}$ phenylmethylsulfonyl fluoride, $1 \%$ Triton $\mathrm{X}-100,1 \mathrm{mM}$ sodium vanadate, and $1 \mathrm{~g} / \mathrm{ml}$ of leupeptin, pepstatin and aprotinin. Cell lysates were incubated on ice for $30 \mathrm{~min}$ and then centrifuged at 12000 r.p.m. for $10 \mathrm{~min}$ at $4^{\circ} \mathrm{C}$. The supernatant was collected and protein content assayed colorimetrically. Ten micrograms of total proteins was loaded onto a $10 \%$ gradient polyacrylamide gel, electrophoretically transferred to a polyvinylidene difluoride membrane and probed with rabbit anti-LC3B antibody (1:1000; Cell Signaling) and mouse anti-NF- $\kappa$ B p65 (1:1000; Cell Signaling). Monoclonal anti- $\beta$-actin (1:1000; Sigma-Aldrich) was used as an internal control. Secondary antibodies were horseradish peroxidase conjugated to goat anti-mouse IgG (1:5000; Sigma-Aldrich). The membranes were developed using an ECL detection system (Pierce, Rockford, IL, USA). The intensity of bands was determined using the Gel pro 4.0 software.

\section{Behavioral Tests}

The Basso Mouse Scale (BMS) for locomotion was used to assess the degree of motor dysfunction after SCI. ${ }^{28,29}$ All mice were gently handled and allowed to walk in an open field to acclimatize them to the apparatus for several days before induction of SCI. The mice were tested before injury, to ensure that they demonstrated equivalent baseline scores. On each post-SCI day, the mice were observed for 4 min by two independent observers who were blinded as to the treatment group. Scores were assigned for each hindlimb and averaged 
for each day. The data analyses were performed on these means.

\section{Statistical Analysis}

Data presented in the text and figures are expressed as the mean \pm s.d. for at least three experiments. The data were analyzed using the Student's $t$-test. The differences were considered statistically significant when the $P$-value was $<0.05$.

\section{RESULTS}

G-CSF Promoted the Improvement of Neuronal Structure and Locomotor Recovery After SCI

Morphological changes of neurons were observed by crystal violet staining and electron microscopy near the epicenter at 5 days after spinal cord hemisection. Crystal violet staining of the dorsal horn area revealed shrunken neurons and fewer Nissl bodies in the control group as compared with that in G-CSF-treated group (Figures $1 \mathrm{a}$ and $\mathrm{b}$ ).

Ultrastructural analysis showed clear degeneration within portions of the myelin sheath with layers of myelin sheath being separated and isolated from the neuraxis in the injured group and the neuraxis was swollen. In the G-CSF group, the myelin sheath was relatively dense with some minor separation of layers being present within portions of the myelin sheath (Figure 1c).

To evaluate the effects of G-CSF upon behavioral responses after acute SCI, BMS scores were assessed at 1-7 days after spinal cord hemisection. Averages of BMS scores at the different time points are summarized in Figure 1d. BMS scores were significantly increased in the G-CSF group versus those in the injury control group at 5 days after spinal cord hemisection. BMS scores of the G-CSF group varied around 4 , with occasional plantar stepping being observed. At 7 days after SCI, scores were about 6 with mice in G-CSF group showing frequent episodes of coordinated plantar stepping. By contrast, only dorsal stepping and occasional plantar stepping at 7 days after spinal cord hemisection were present within the injury control group.

\section{G-CSF Induced Activation of Autophagy After SCI}

To examine whether autophagy was activated in response to SCI, immunohistochemical staining and western blots for LC3B and electron microscopic analysis in the peri-lesioned spinal cord tissue were performed at 1, 3, 5 and 7 days after spinal cord hemisection. Immunohistochemical staining showed that cells expressing LC3B were increased on the injured versus contralateral side on each of the days sampled after spinal cord hemisection (Figures $2 \mathrm{a}$ and $\mathrm{j}$ ). LC3Bpositive cells were mainly located in the gray matter of the injured side and diminished as a function of distance from the injury site. The number of LC3B-positive cells was relatively higher at 3 and 5 days than at the other time points (Figures $2 \mathrm{a}$ and $\mathrm{j}$ ). Ultrastructural analysis revealed that autophagosomes, containing cytoplasmic material and wrapped by double-membrane structures, were visible in the damaged neurons at 5 days after SCI (Figure $2 \mathrm{k}$ ).

To detect whether G-CSF treatment modified autophagy activation after SCI, western blots for LC3B in the perilesioned spinal cord tissue were performed at 1, 3, 5 and 7 days after spinal cord hemisection. LC3B expression was observed at an earlier time point $(1 \mathrm{~h})$ in the G-CSF versus that of the control group ( $4 \mathrm{~h}$ ) (data not shown). Levels of LC3B protein were significantly increased in the G-CSF group as compared with that in the control group during the first 5 days post-lesion, with maximal differences being observed at 3 and 5 days after spinal cord hemisection (Figures 21 and $\mathrm{m})$. Although LC3B expression at 7 days remained increased, these levels failed to differ significantly from that of the control group (Figures $2 \mathrm{l}$ and $\mathrm{m}$ ). In this way, G-CSF treatment appears to advance the onset time for initiating autophagy and maintains increased levels for longer durations in the injured spinal cord. Notably, we found that LC3B expression persisted for 1 month after SCI (data not shown). These findings suggesting that G-CSF may induce a rapid onset and prolonged activation of autophagy in response to SCI.

\section{Autophagy was Present Mainly in Neurons After SCI}

To identify LC3B-positive cells within the injured spinal cord, tissues were double stained with LC3B and MAP2/GFAP at 5 days after SCI. LC3B-positive punctuated dots were sparse on the injured side of spinal cord (Figure 3a). LC3B was expressed within neurons co-labeled with the neuronal marker, MAP2 (Figure 3b). Very few astrocytes expressed LC3B (Figure 3c).

\section{Autophagy Activation Inhibited Apoptosis After Injury}

To examine whether autophagy affected apoptosis after injury, double staining for LC3B and TUNEL was performed at 5 days after spinal cord hemisection. Near the site of injury, elevated amounts of TUNEL-positive and LC3B-positive cells were detected. Moreover, some TUNEL-positive cells were also LC3B positive, a finding that was most frequently observed in G-CSF-treated mice (Figures 4a and d). Notably, most nuclei of LC3B-positive cells that were TUNEL positive were round and not shrunken or fragmented, as is typical of apoptotic nuclei (Figures $4 \mathrm{a}$ and d). The expression of LC3B and morphology of these nuclei suggest that in at least some of the injured neurons autophagy may have protected these neurons from apoptosis after injury. In fact, more TUNELpositive cells were present in the injured mice without G-CSF treatment than in that of G-CSF-treated mice (Figure 4e).

\section{3-MA Partially Blocks the Neuroprotective Activity of G-CSF in Cultured Neurons}

To investigate the possibility that autophagy is involved in the neuroprotective effect of G-CSF on neurons, we established a neuronal mechanical injury model in these cultured neurons. The specific inhibitor of autophagy, 3-MA, was then added in 
a
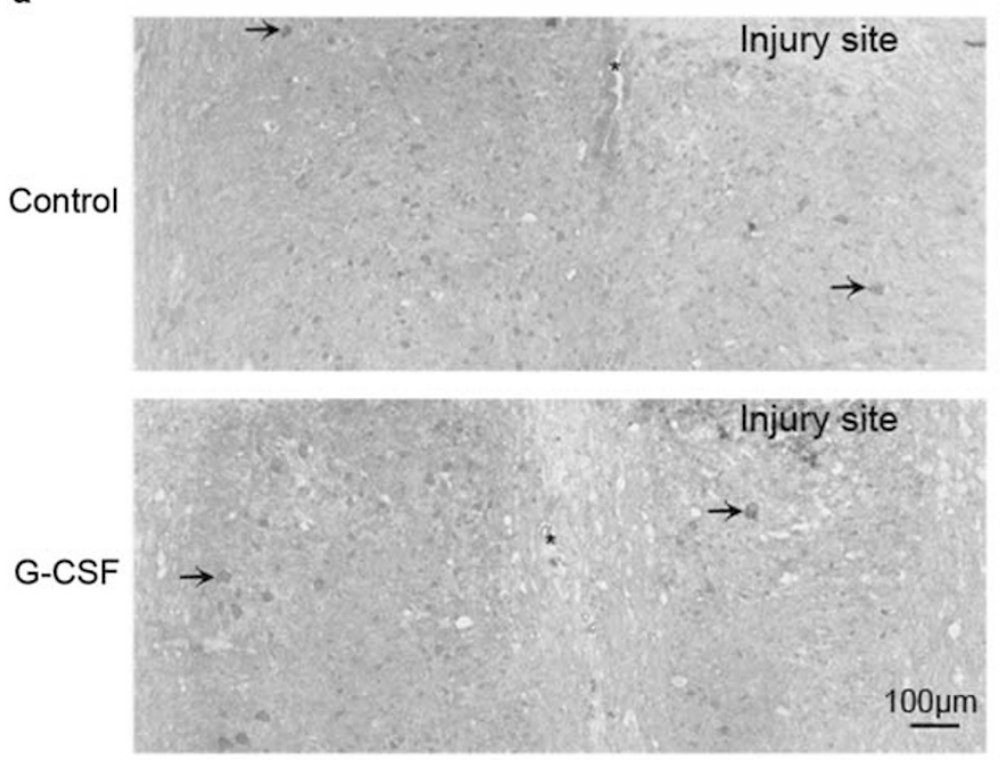

b
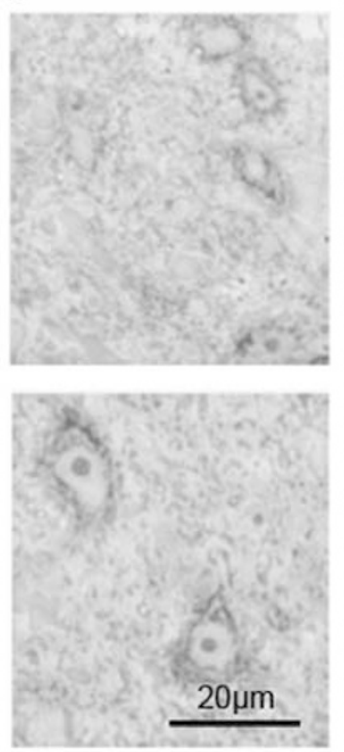

c
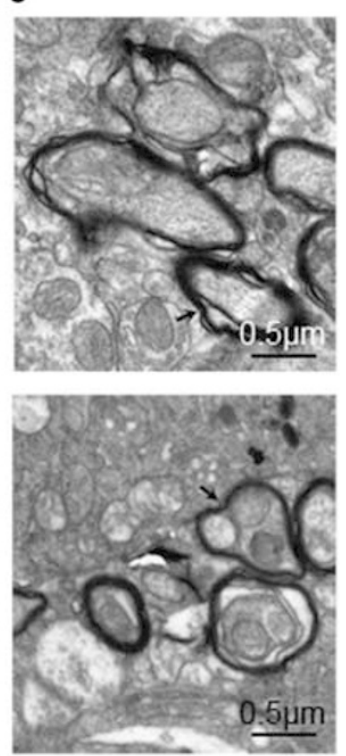

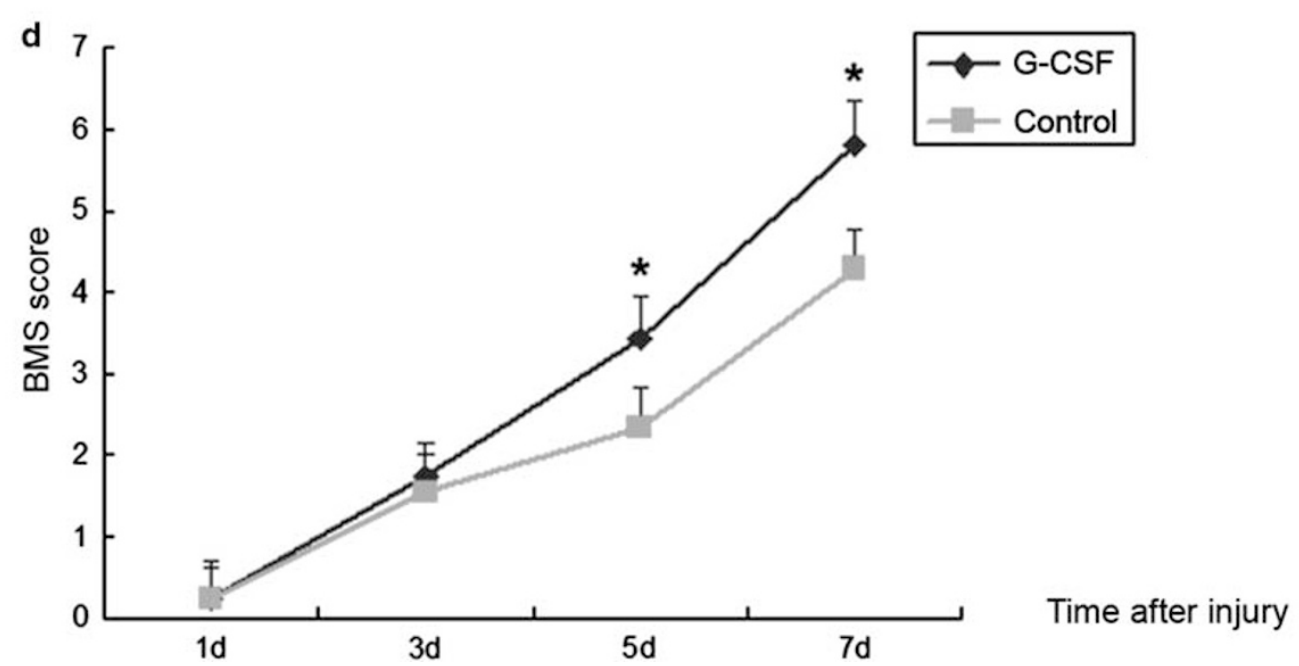

Figure 1 G-CSF promoted improvement in neuronal structure and locomotor recovery after SCl. (a) Crystal violet staining of the dorsal horn area near the epicenter of spinal cord hemisection as performed at 5 days post-SCl. Crystal violet staining revealed that neurons shrunk and contained fewer Nissl bodies in the control group as compared with that in G-CSF-treated group. (b) Magnified images of neurons. (c) Spinal cord neuronal structures as observed using electron microscopy at 5 days after spinal cord hemisection. Degeneration of the myelin sheath in the injury group was indicated by the substantial amount of myelin separation, as indicated by the arrows. (d) G-CSF improved locomotor function after SCl. The degree of motor impairment was assessed in a blinded manner using the BMS protocol. Scores range from 0 (complete paralysis) to 9 (normal movement of the hindlimbs). Scores were assigned by two naive observers for each right hindlimb and averaged for each mouse. Mice treated with G-CSF demonstrated marked improvement at 5 and 7 days and were statistically different as compared with the control group $\left.{ }^{*} P<0.05\right)$. Data are means \pm s.d. of six mice per group. A full color version of this figure is available at the Laboratory Investigation journal online.

the presence of G-CSF in this model to determine whether the neuroprotective effect of G-CSF was altered after inhibiting the activation of autophagy. MDC staining revealed that autophagy was induced in neurons when they were treated with G-CSF after mechanical injury (Figure 5a). LC3B immunofluorescence staining indicated that the expression of LC3B was significantly increased in the G-CSF group as compared with that of the control group (Figure 5b). Moreover, we found more TUNEL-positive cells in the 3-MA-treated mechanically injured neurons than that in the
G-CSF group (Figure 5c). These results show that the neuroprotective activity of G-CSF in injured neurons was partially blocked after inhibiting autophagy by 3 -MA.

\section{NF-KB is Involved in G-CSF-Induced Activation of Autophagy After Mechanical Injury of Cultured Neurons}

We next determined whether the NF- $\kappa \mathrm{B}$ signaling pathway was involved in G-CSF-induced autophagy in neurons in this mechanical injury model, like that observed in the cardiomyopathic hamster model. ${ }^{21}$ Therefore, we examined NF- $\kappa$ B 

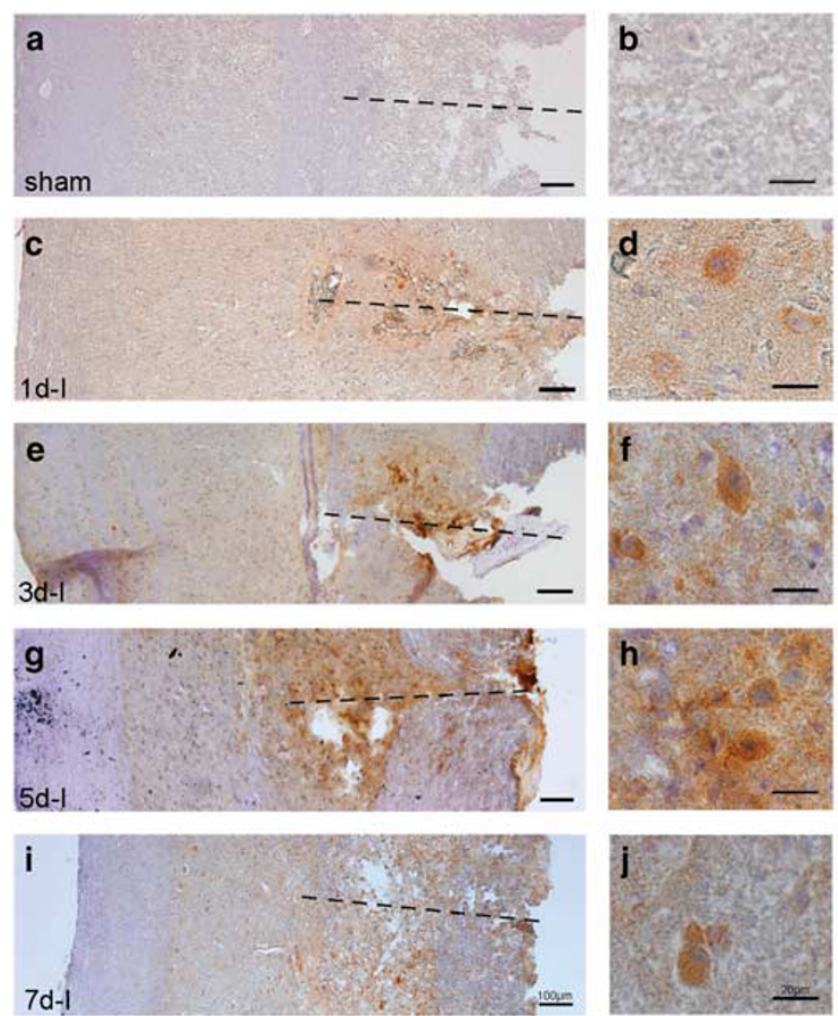

k
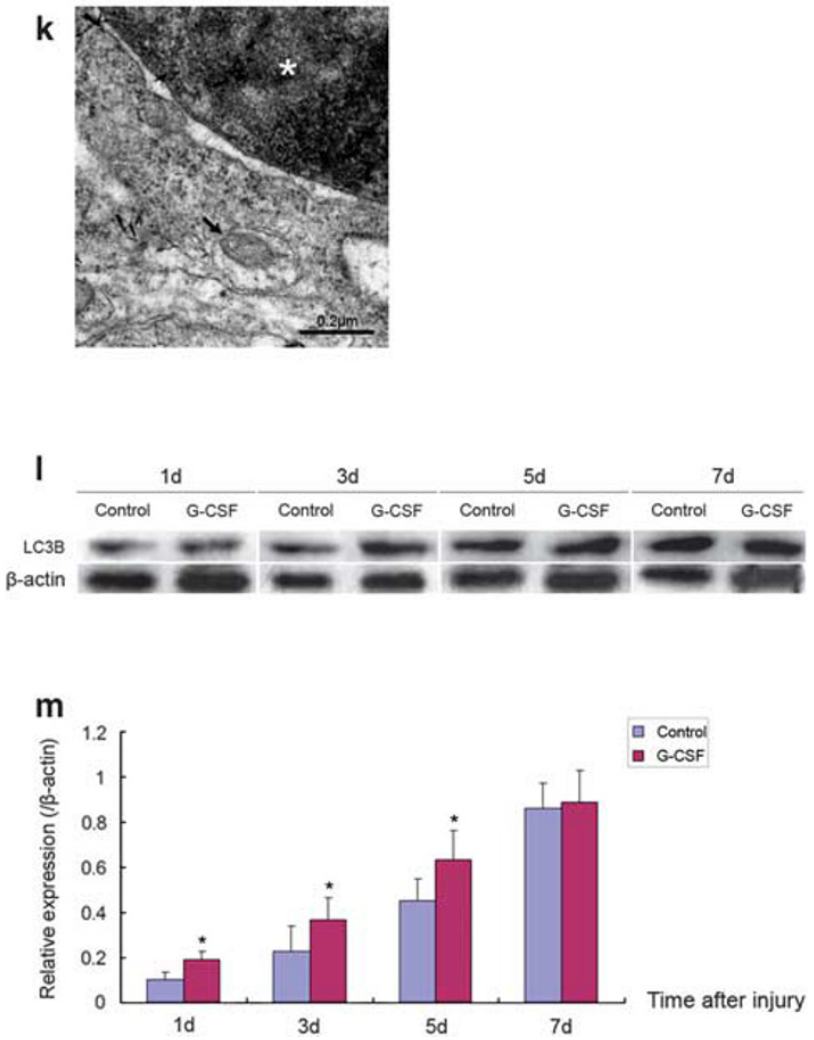

Figure 2 G-CSF induced activation of autophagy after SCl. (a-j) Immunohistochemical staining of LC3B in longitudinal sections at different time points. The expression of LC3B was increased at 1, 3, 5 and 7 days in comparison with the control group. The population of the LC3B-expressing cells was relatively higher at 3 and 5 days than at the other time points. (k) Electron micrographs of the dorsal horn area near the lesion epicenter at 5 days after spinal cord hemisection. Autophagic vesicles containing portions of the cytoplasm and wrapped by double-membrane structures were observed in the damaged cells $(\rightarrow)$. (I) The expression of LC3B in the injured spinal cord after spinal cord hemisection as assessed using western blot. Increased levels of LC3B were expressed in the injured spinal cord within 1 day and peaked at 7 days after spinal cord hemisection. (m) Histograms of relative protein LC3B levels in the injured spinal cord $\left.{ }^{*} P<0.05\right)$. Each value was normalized to $\beta$-actin. Statistical analysis indicated that the expression of $L C 3 B$ significantly upregulated in G-CSF group after acute $\mathrm{SCl}$ as compared with that in control group.

activation in mechanically injured neurons treated with G-CSF. Western blot analysis revealed that G-CSF treatment significantly reduced the expression of NF- $\kappa \mathrm{B}$ p 65 in neurons after mechanical injury (Figures $6 a$ and $b$ ).

To further determine the role of NF- $\kappa \mathrm{B}$ in the SCI-induced autophagy, we added BAY11-7082 (NF- $\kappa \mathrm{B}$ inhibitor) to neuronal mechanical injury model and examined the LC3B expression in neurons after mechanical injury. Western blot results showed that the expression of LC3B was upregulated after treatment of NF- $\kappa \mathrm{B}$ inhibitor (Figures $6 \mathrm{c}$ and $\mathrm{d}$ ). Compared with the expression of LC3B in G-CSF group, there was no significant difference. These results show that inhibiting NF- $\kappa$ B pathway may mimic the autophagy activation by G-CSF in injured neurons.

\section{DISCUSSION}

After SCI, spinal cord tissue is in a state of stress, which results in apoptosis of neurons at the injury site. Autophagy is generally maintained at a low level in cells but is activated to promote cell survival through the degradation of excess or damaged organelles and proteins during conditions of stress. Recently, it has been reported that autophagy has a key role in injured spinal cord tissue. ${ }^{6,30,31}$ In this study, we report that autophagy is activated at the injury site after SCI. LC3B expression is increased, beginning at $4 \mathrm{~h}$ and peaking at 7 days after SCI. The time course of this LC3B expression is quite similar to that of apoptosis after SCI. Moreover, we found that this LC3B expression is upregulated mainly in neurons. In line with our results are the findings that LC3B is expressed mainly in neurons after early CNS damage. ${ }^{15,32,33}$ It is noteworthy that G-CSF can induce autophagy activation in the injured spinal cord, which contributes to promote improvement in neuronal structure and locomotor recovery after SCI. G-CSF is one example of a hematopoietic growth factor with a low molecular weight. It can pass through the blood-brain barrier to enter the CNS. ${ }^{34,35}$ Moreover, accumulating evidence has shown that G-CSF also has important non-hematopoietic functions in the CNS. ${ }^{36,37} \mathrm{We}$ reported previously that G-CSFR was expressed specifically 
a

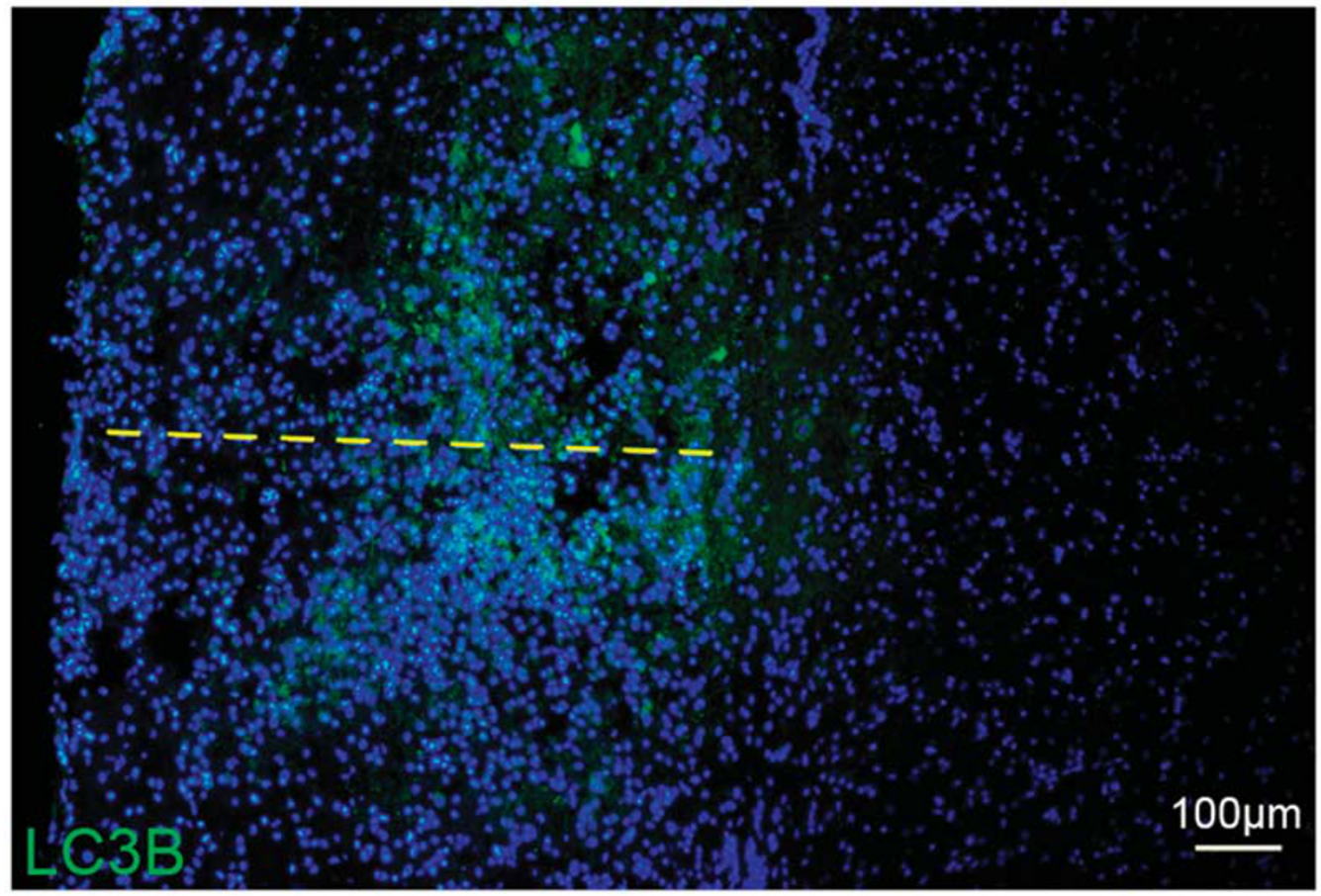

b
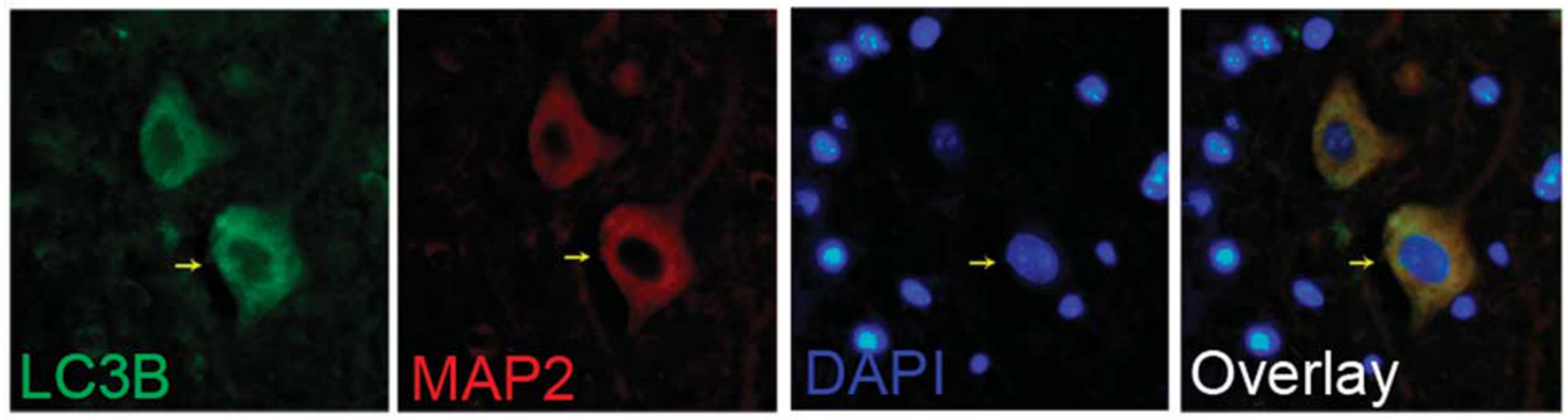

C
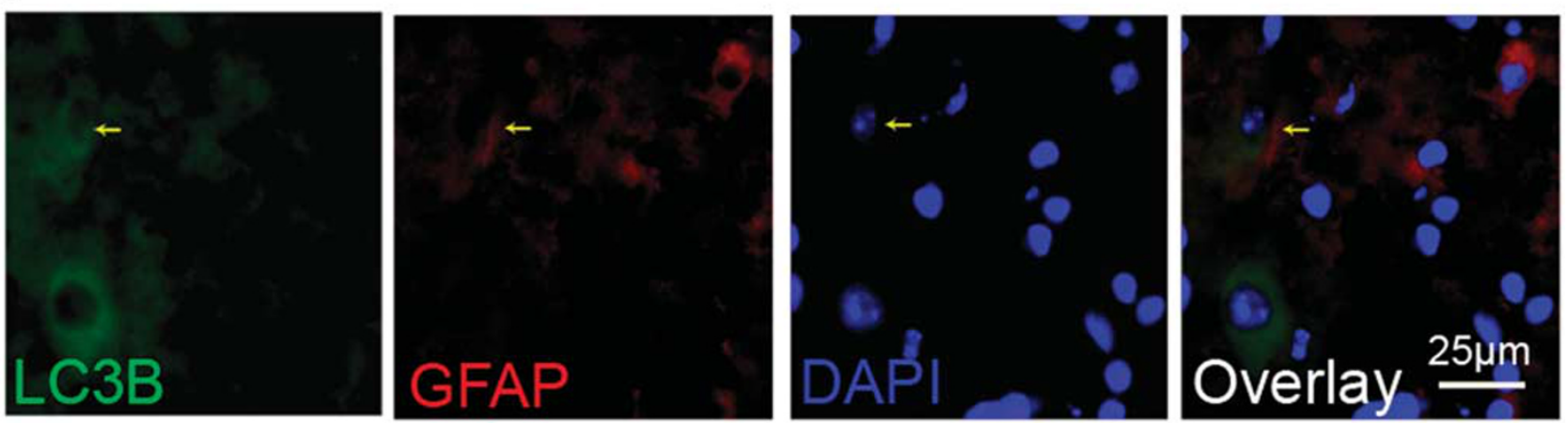

Figure 3 Localization of LC3B by double immunofluorescence staining within the spinal cord at 5 days after spinal cord hemisection. (a) LC3B-positive punctuated dots were sparse in the injured spinal cord at 5 days after spinal cord hemisection. (b) Co-staining of MAP2 and LC3B in the injured spinal cord (arrows indicated co-staining cells). (c) Co-staining of GFAP and LC3B in the injured spinal cord (arrows indicate co-staining cells).

within neurons of the spinal cord ${ }^{38}$ and in this study we find that autophagy also occurs in these neurons. The induction of autophagy activation in the injured spinal cord by G-CSF may begin as early as at $1 \mathrm{~h}$ after SCI and this autophagy response in G-CSF-treated mice is slightly higher than that of the non-treated animals. One possible explanation for this effect of G-CSF is an elevation in LC3B levels that reach maximal values in response to G-CSF treatment. This upregulation of 

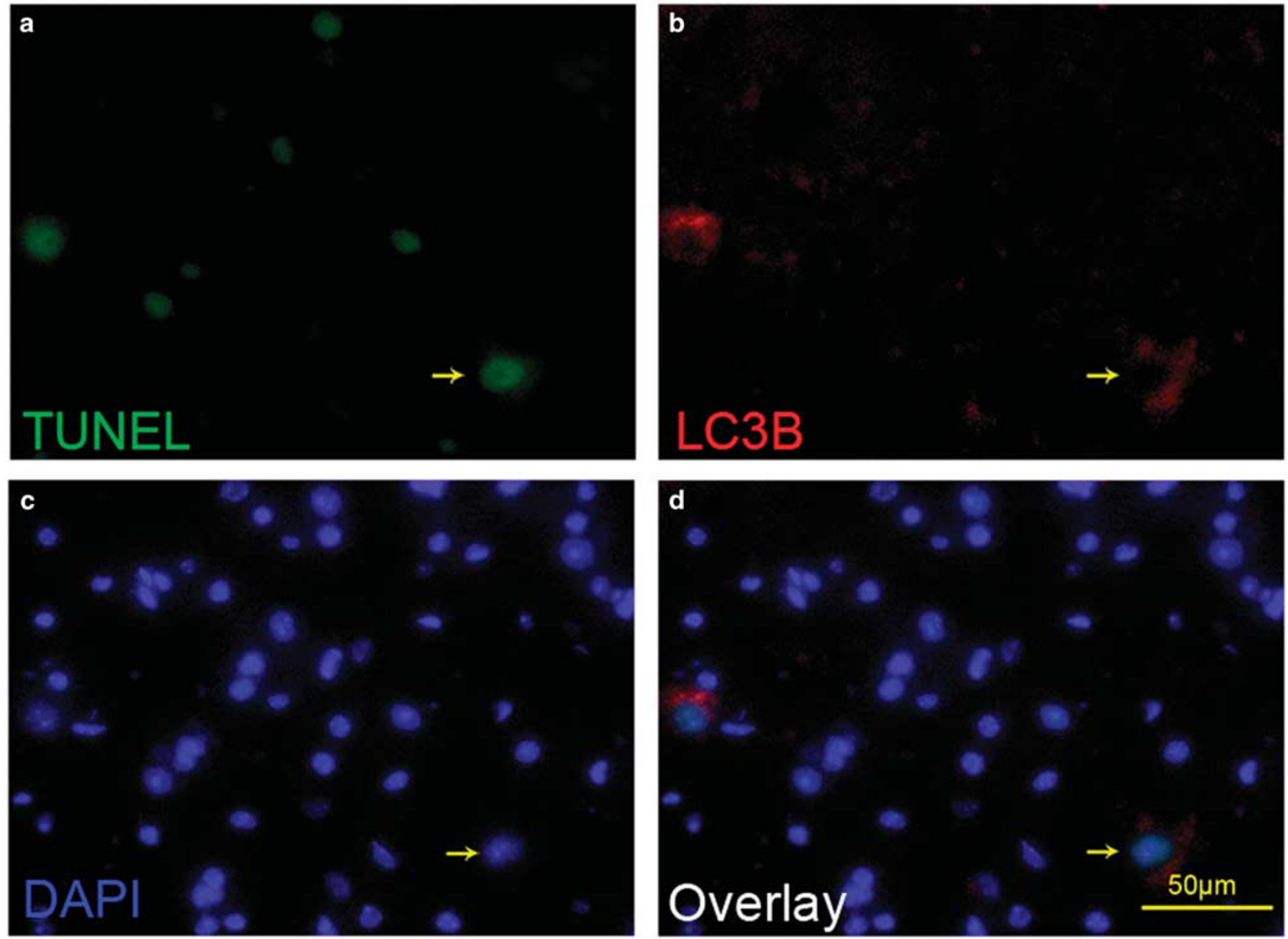

e *

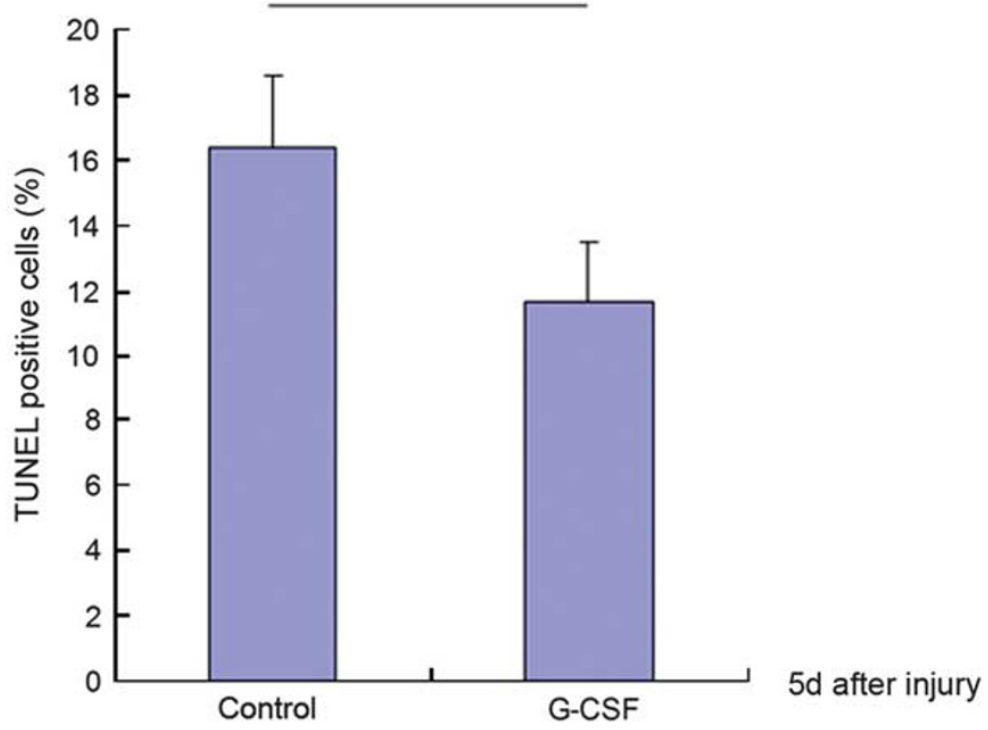

Figure 4 Co-staining of LC3B and TUNEL in the injured spinal cord at 5 days after spinal cord hemisection. (a-d) Representative sections at the epicenter show that some LC3B-positive neurons also showed TUNEL staining in the injured spinal cord (arrows indicated co-staining cells). (e) Quantitative analysis of TUNEL-positive cell numbers. The number of TUNEL-positive cells was significantly decreased in G-CSF-treated mice as compared with that in the control group. Values are means \pm s.d. $\left({ }^{*} P<0.05, n=6\right.$ per each group). 


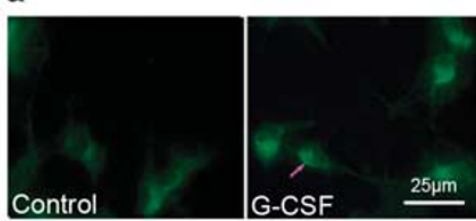

C
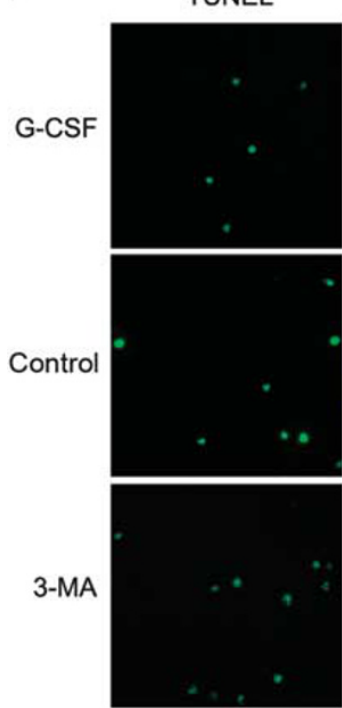
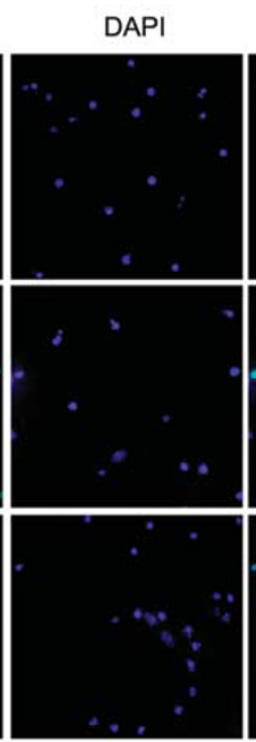
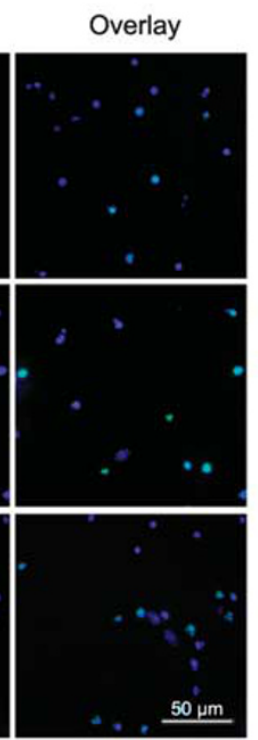

b
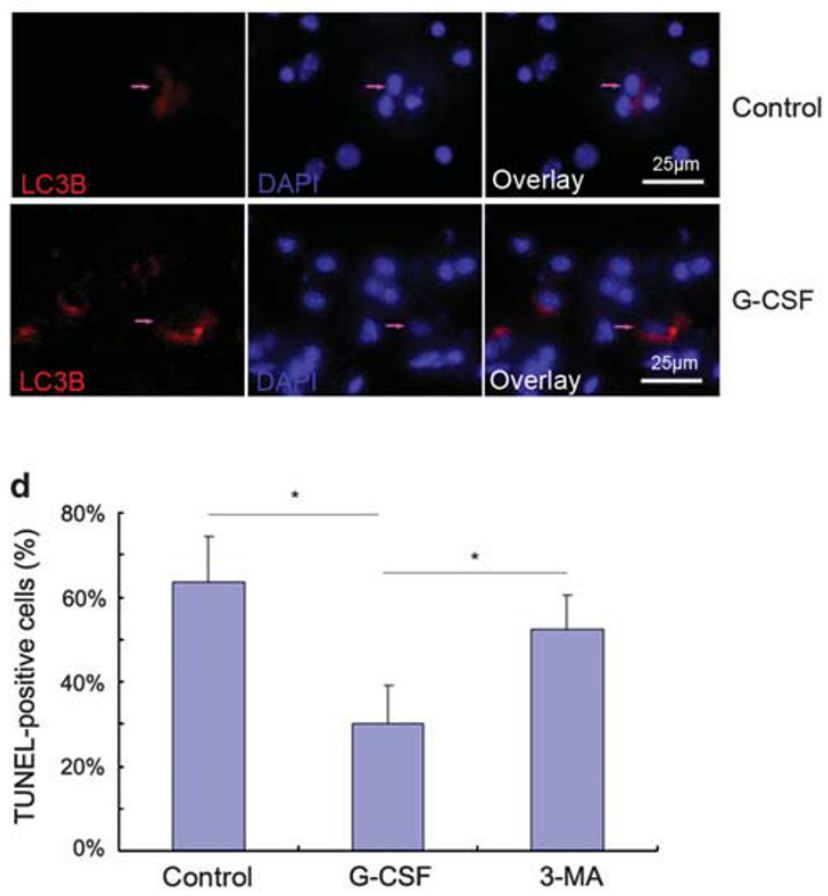

Figure 5 3-MA partially blocked neuroprotective activity of G-CSF in cultured neurons. (a) MDC staining of neurons after mechanical injury. Autophagic vacuoles were detected by MDC staining (arrows indicated autophagic vacuoles). The fluorescence signal in the G-CSF group is stronger than that in control group. (b) LC3B immunofluorescence staining of neurons after neuronal mechanical injury. LC3B immunofluorescence staining indicated that the expression of LC3B was significantly increased in the G-CSF group as compared with that of the control group (arrows indicated LC3B-positive cells). (c) TUNEL staining of neurons after neuronal mechanical injury. (d) Quantitative analysis of TUNEL-positive cell numbers. The number of TUNEL-positive cells was significantly decreased in G-CSF-treated mechanically injured neurons as compared with that of the control group and 3-MA group. Values are means \pm s.d. $\left({ }^{*} P<0.05, n=3\right.$ per each group).

LC3B may maximize and prolong autophagy activity in neurons after treatment with G-CSF.

Interestingly, we also find that most nuclei of LC3Bpositive cells that are TUNEL positive are round and not shrunken or fragmented, suggesting that in at least some of these injured neurons autophagy may have an important protective role by inhibiting apoptosis at this early stage of SCI, a conclusion supported by Kanno et al. ${ }^{7}$ The role of autophagy activation during SCI remains a matter of debate. Many investigators regard autophagy as exerting a cytoprotective function that involves a mechanism for recycling injured cells and reducing damage against cell death. ${ }^{15,39-41}$ However, others have reported that autophagy mainly has a destructive role by inducing cell death in CNS injury. ${ }^{42,43}$ To address this issue, we treated mice with 3 -MA at $10 \mathrm{~min}$ before neuronal mechanical injury. Our results show that 3-MA significantly increases TUNEL-positive neurons at $24 \mathrm{~h}$ after SCI. These results indicate that apoptosis in the injured neurons is aggravated after inhibiting autophagy by 3-MA. Therefore, the neuroprotection of G-CSF may, in part, be related to a rapid onset activation of autophagy.
Most importantly, our results show that G-CSF inhibits activity of NF- $\kappa$ B signal pathway in neurons after mechanical injury. Although $\mathrm{NF}-\kappa \mathrm{B}$-induced responses are most commonly associated with immunological and inflammatory processes, the role of $\mathrm{NF}-\kappa \mathrm{B}$ in pathological neuronal functions has not been well established. It has been shown that SCI can inhibit the production of protective $i \kappa \mathrm{B}$, promote $\mathrm{NF}-\kappa \mathrm{B}$ within the nucleus ${ }^{44}$ and NF- $\kappa \mathrm{B}$ activation will in turn aggravate effects of an injury and neuronal degeneration. ${ }^{45}$ $\mathrm{NF}-\kappa \mathrm{B}$ activation is also detected in cerebellar granule cells after exposure to glutamate. ${ }^{46}$ Moreover, in these studies an inhibition of $\mathrm{NF}-\kappa \mathrm{B}$ activation prevented neuronal cell death. ${ }^{47}$ Autophagy is associated with a particular type of cellular death and has an important role in the degradation of cytoplasmic constituents in the autophagosomal-lysosomal pathway. ${ }^{8,9}$ In this report, we highlight the significance of the $\mathrm{NF}-\kappa \mathrm{B}$ family member p65 to control autophagy induced by G-CSF. Consistent with this postulate are the findings that $\mathrm{NF}-\kappa \mathrm{B}$ activation mediates repression of autophagy in tumor necrosis factor-alpha-treated Ewing sarcoma cells and inhibition of $\mathrm{NF}-\kappa \mathrm{B}$ results in an enhancement of ischemia-induced 


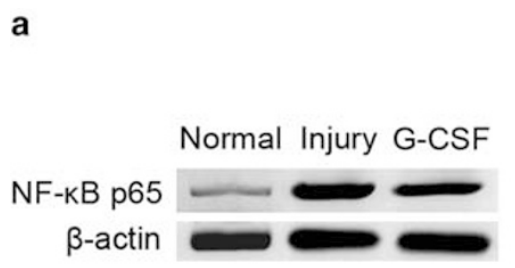

C

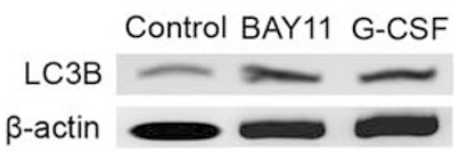

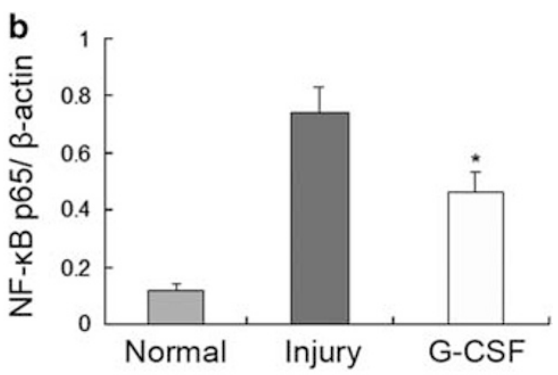

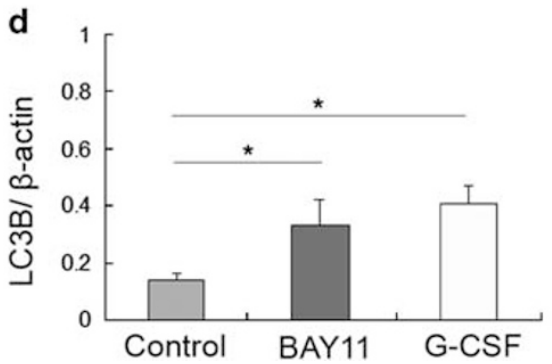

Figure 6 NF-KB signaling pathway involvement in G-CSF-induced autophagy in neuronal mechanical injury. (a) Expression of NF- $\kappa B$ p65 in mechanically injured neurons was determined by western blot. (b) Histograms showing relative protein levels of NF- $k B$ p65 in the neurons (* $P<0.05$ ). Each value was normalized to $\beta$-actin. Expression of NF-KB p65 was significantly decreased in neurons treated with G-CSF as compared with the control group. (c) The expression of LC3B in mechanically injured neurons was assessed using western blot. Increased levels of LC3B were expressed in the G-CSF group and BAY11 group. (d) Histograms showing relative protein levels of LC3B in mechanically injured neurons $\left({ }^{*} P<0.05\right)$. Each value was normalized to $\beta$-actin. Expression of LC3B was significantly increased in neurons treated with G-CSF and BAY11 as compared with the control group. There was no significant difference between G-CSF group and BAY11 group. A full color version of this figure is available at the Laboratory Investigation journal online.

autophagy. ${ }^{48,49}$ However, it has also been reported that p65 binds to the promoter of the essential autophagic gene BECN1 and regulates its expression in response to ceramide and tamoxifen treatment. ${ }^{50}$ Inhibition of NF- $\kappa$ B leads to decreased expression of three autophagy-related genes-ATG101, ATG7 and GABARAPL1. ${ }^{51}$ Taken together, activation of NF- $\kappa \mathrm{B}$ and autophagy represent two processes involved in the regulation of cell death. Further studies are needed to establish the possible cross-talk between these two signaling pathways.

A wealth of evidence suggests that initial (within hours) inflammatory responses contribute to later stages of CNS injury and result in a worsening of the neurological outcome. ${ }^{52,53}$ A rapid induction of autophagy to injury may contribute to maintenance of local microenvironmental homeostasis and alleviation of neuronal damage. We therefore suggest that G-CSF, which induces autophagy and applies as soon as possible after SCI, would inhibit neuronal apoptosis and thus provide an effective auxiliary therapeutic intervention for SCI.

\section{ACKNOWLEDGMENTS}

This work is supported by the National Natural Science Foundation of China (grant no. 81100919); special financial grant from the China postdoctoral science foundation (2014T70647); postdoctoral science foundation of Shandong province (201203050); the Scientific Research Foundation for Returned Scholars, Ministry of Education of China (21300005451001); Shangdong Province Young and Middle-Aged Scientists Research Awards Fund (BS2010YY041); Natural Science Foundation of Shandong Province (2012GSF11842; ZR2011HL070, ZR2015HM030).

\section{DISCLOSURE/CONFLICT OF INTEREST}

The authors declare no conflict of interest.

1. Horner PJ, Power AE, Kempermann $G$ et al. Proliferation and differentiation of progenitor cells throughout the intact adult rat spinal cord. J Neurosci 2000;20:2218.

2. Guest JD, Hiester ED, Bunge RP. Demyelination and Schwann cell responses adjacent to injury epicenter cavities following chronic human spinal cord injury. Exp Neurol 2005;192:384-393.

3. Wilhelmsson U, Bushong EA, Price DL et al. Redefining the concept of reactive astrocytes as cells that remain within their unique domains upon reaction to injury. Proc Natl Acad Sci USA 2006;103:17513-17518.

4. Crowe MJ, Bresnahan JC, Shuman SL et al. Apoptosis and delayed degeneration after spinal cord injury in rats and monkeys. Nat Med 1997;3:73-76.

5. Profyris C, Cheema SS, Zang D et al. Degenerative and regenerative mechanisms governing spinal cord injury. Neurobiol Dis 2004;15: 415-436.

6. Kanno H, Ozawa H, Sekiguchi A et al. Spinal cord injury induces upregulation of Beclin 1 and promotes autophagic cell death. Neurobiol Dis 2009;33:143-148.

7. Kanno H, Ozawa $H$, Sekiguchi $A$ et al. The role of autophagy in spinal cord injury. Autophagy 2009;5:390-392.

8. Mizushima N, Yamamoto $\mathrm{A}$, Matsui $\mathrm{M}$ et al. In vivo analysis of autophagy in response to nutrient starvation using transgenic mice expressing a fluorescent autophagosome marker. Mol Biol Cell 2004;15:1101-1111.

9. Kabuta T, Furuta A, Aoki $\mathrm{S}$ et al. Aberrant interaction between Parkinson disease-associated mutant UCH-L1 and the lysosomal receptor for chaperone-mediated autophagy. J Biol Chem 2008;283: 23731-23738.

10. Meredith GE, Totterdell S, Petroske E et al. Lysosomal malfunction accompanies alpha-synuclein aggregation in a progressive mouse model of Parkinson's disease. Brain Res 2002;956:156-165.

11. Nixon RA. Autophagy, amyloidogenesis and Alzheimer disease. J Cell Sci 2007;120(Pt 23):4081-4091. 
12. Kim J, Kim TY, Cho KS et al. Autophagy activation and neuroprotection by progesterone in the G93A-SOD1 transgenic mouse model of amyotrophic lateral sclerosis. Neurobiol Dis 2013;59:80-85.

13. Matsui $\mathrm{Y}$, Kyoi $\mathrm{S}$, Takagi $\mathrm{H}$ et al. Molecular mechanisms and physiological significance of autophagy during myocardial ischemia and reperfusion. Autophagy 2008;4:409-415.

14. Diskin $\mathrm{T}$, Tal-Or $\mathrm{P}$, Erlich $\mathrm{S}$ et al. Closed head injury induces upregulation of Beclin 1 at the cortical site of injury. J Neurotrauma 2005:22:750-762.

15. Rami A, Langhagen A, Steiger S. Focal cerebral ischemia induces upregulation of Beclin 1 and autophagy-like cell death. Neurobiol Dis 2008:29:132-141.

16. Welte K, Platzer E, Lu L et al. Purification and biochemical characterization of human pluripotent hematopoietic colonystimulating factor. Proc Natl Acad Sci USA 1985;82:1526-1530.

17. Pan HC, Cheng FC, Lai SZ et al. Enhanced regeneration in spinal cord injury by concomitant treatment with granulocyte colony-stimulating factor and neuronal stem cells. J Clin Neurosci 2008;15:656-664.

18. Henriques A, Pitzer C, Dupuis L et al. G-CSF protects motoneurons against axotomy-induced apoptotic death in neonatal mice. BMC Neurosci 2010;11:25.

19. Nishio $Y$, Koda M, Kamada $T$ et al. Granulocyte colony-stimulating factor attenuates neuronal death and promotes functional recovery after spinal cord injury in mice. J Neuropathol Exp Neurol 2007;66: 724-731.

20. Yamasaki R, Tanaka M, Fukunaga $M$ et al. Restoration of microglial function by granulocyte-colony stimulating factor in ALS model mice. J Neuroimmunol 2010;229:51-62.

21. Miyata S, Takemura G, Kawase $Y$ et al. Autophagic cardiomyocyte death in cardiomyopathic hamsters and its prevention by granulocyte colony-stimulating factor. Am J Pathol 2006;168:386-397.

22. Arvanian VL, Schnell L, Lou $L$ et al. Chronic spinal hemisection in rats induces a progressive decline in transmission in uninjured fibers to motoneurons. Exp Neurol 2009;216:471-480.

23. Guo $\mathrm{Y}$, Zhang $\mathrm{H}$, Yang $\mathrm{J}$ et al. Granulocyte colony-stimulating factor improves alternative activation of microglia under microenvironment of spinal cord injury. Neuroscience 2013;238:1-10.

24. Bartolini A, Vigliani MC, Magrassi L et al. G-CSF administration to adult mice stimulates the proliferation of microglia but does not modify the outcome of ischemic injury. Neurobiol Dis 2011;41:640-649.

25. Das $M$, Patil S, Bhargava N et al. Auto-catalytic ceria nanoparticles offer neuroprotection to adult rat spinal cord neurons. Biomaterials 2007;28: 1918-1925.

26. Ma $\mathrm{YH}$, Zeng $\mathrm{X}$, Zhang $\mathrm{K}$ et al. A new in vitro injury model of mouse neurons induced by mechanical scratching. Neurosci Lett 2012;510:14-19.

27. An HK, Kim KS, Lee JW et al. Mimulone-induced autophagy through p53-mediated AMPK/mTOR pathway increases caspase-mediated apoptotic cell death in A549 human lung cancer cells. PLoS One 2014;9:e114607.

28. Basso DM, Fisher LC, Anderson AJ et al. Basso mouse scale for locomotion detects differences in recovery after spinal cord injury in five common mouse strains. J Neurotrauma 2006:23:635-659.

29. Campolo M, Esposito E, Ahmad A et al. A hydrogen sulfide-releasing cyclooxygenase inhibitor markedly accelerates recovery from experimental spinal cord injury. FASEB J 2013;27:4489-4499.

30. Chen HC, Fong TH, Lee AW et al. Autophagy is activated in injured neurons and inhibited by methylprednisolone after experimental spinal cord injury. Spine (Phila Pa 1976) 2012;37:470-475.

31. Fan J, Zhang $Z$, Chao $X$ et al. Ischemic preconditioning enhances autophagy but suppresses autophagic cell death in rat spinal neurons following ischemia-reperfusion. Brain Res 2014;1562:76-86.
32. Yan $\mathrm{W}$, Zhang $\mathrm{H}$, Bai $\mathrm{X}$ et al. Autophagy activation is involved in neuroprotection induced by hyperbaric oxygen preconditioning against focal cerebral ischemia in rats. Brain Res 2011;1402:109-121.

33. Fujita S, Sakurai M, Baba $\mathrm{H}$ et al. Autophagy-mediated stress response in motor neurons after hypothermic spinal cord ischemia in rabbits. J Vasc Surg 2015;62:1312-1319.

34. Pitzer C, Krüger C, Plaas $C$ et al. Granulocyte-colony stimulating factor improves outcome in a mouse model of amyotrophic lateral sclerosis. Brain 2008:131:3335-3347.

35. Zhao LR, Navalitloha $Y$, Singhal $S$ et al. Hematopoietic growth factors pass through the blood-brain barrier in intact rats. Exp Neurol 2007;204:569-573.

36. Sanli AM, Serbes G, Calişkan M et al. Effect of granulocyte-colony stimulating factor on spinal cord tissue after experimental contusion injury. J Clin Neurosci 2010;17:1548-1552.

37. Dittgen $T$, Pitzer $C$, Plaas $C$ et al. Granulocyte-colony stimulating factor (G-CSF) improves motor recovery in the rat impactor model for spinal cord injury. PLoS One 2012;7:e29880.

38. Guo Y, Liu S, Wang P et al. Granulocyte colony-stimulating factor improves neuron survival in experimental spinal cord injury by regulating nucleophosmin-1 expression. J Neurosci Res 2014;92: 751-760.

39. Smith $C M$, Chen $Y$, Sullivan $M L$ et al. Autophagy in acute brain injury: feast, famine, or folly?Neurobiol Dis 2011;43:52-59.

40. Kanno H, Ozawa H, Sekiguchi A et al. Induction of autophagy and autophagic cell death in damaged neural tissue after acute spinal cord injury in mice. Spine (Phila Pa 1976) 2011;36:E1427-E1434.

41. Tang $P$, Hou $H$, Zhang $L$ et al. Autophagy reduces neuronal damage and promotes locomotor recovery via inhibition of apoptosis after spinal cord injury in rats. Mol Neurobiol 2014;49:276-287.

42. Shintani T, Klionsky DJ. Autophagy in health and disease: a doubleedged sword. Science 2004;306:990-995.

43. Wen YD, Sheng R, Zhang LS et al. Neuronal injury in rat model of permanent focal cerebral ischemia is associated with activation of autophagic and lysosomal pathways. Autophagy 2008;4:762-769.

44. Bethea JR, Castro M, Keane RW et al. Traumatic spinal cord injury induces nuclear factor-kappaB activation. J Neurosci 1998;18:3251-3260.

45. Grilli $M$, Memo M. Nuclear factor-kB/Rel proteins: a point of convergence of signalling pathways relevant in neuronal function and dysfunction. Biochem Pharmacol 1999;57:1-7.

46. O'Neill LAJ, Kaltschmidt C. NF- $\kappa B$ : a crucial transcription factor for glial and neuronal cell function. Trends Neurosci 1997;20:252-258.

47. Grilli M, Pizzi M, Memo M et al. Neuroprotection by aspirin and sodium salicylate through blockade of NF-kappaB activation. Science 1996;274: 1383-1385.

48. Djavaheri-Mergny M, Amelotti M, Mathieu J et al. NF-kappaB activation represses tumor necrosis factor-alpha-induced autophagy. J Biol Chem 2006:281:30373-30382.

49. Li WL, Yu SP, Chen D et al. The regulatory role of NF- $k B$ in autophagylike cell death after focal cerebral ischemia in mice. Neuroscience 2013;244:16-30

50. Copetti T, Bertoli C, Dalla E et al. p65/RelA modulates BECN1 transcription and autophagy. Mol Cell Biol 2009;29:2594-2608.

51. Shulak L, Beljanski V, Chiang C et al. Histone deacetylase inhibitors potentiate vesicular stomatitis virus oncolysis in prostate cancer cells by modulating NF-KB-dependent autophagy. J Virol 2014;88:2927-2940.

52. Kirino T. Delayed neuronal death. Neuropathology 2000;20(Suppl): S95-S97.

53. Shohami E, Gati I, Beit-Yannai E et al. Closed head injury in the rat induces whole body oxidative stress: overall reducing antioxidant profile. J Neurotrauma 1999;16:365-376. 